УдК 316.772.5:316.612

\title{
ЦИФРОВОЕ ПРОСТРАНСТВО КАК СТИМУЛ ФОРМИРОВАНИЯ ИНДИВИДУАЛИЗАЦИИ И САМООПРЕДЕЛЕНИЯ
}

\author{
Петев Николай Иванович, \\ cyanideemo@mail.ru

\begin{abstract}
Владимирский государственный университет имени А.Г. и Н.Г. Столетовых, Россия, 600000, г. Владимир, ул. Горького, 87
\end{abstract}

Петев Николай Иванович, кандидат философских наук, доцент кафедры философии и религиоведения Владимирского государственного университета имени А.Г. и Н.Г. Столетовых.

В статье рассматривается влияние цифрового пространства на формирование индивидуальности и анализируется её специфика. Иными словами, автор изучает генезис индивидуальности и личностные метаморфозы, которые инициируются под влиянием специфики цифрового мира. Цель работы: выявление специфики формирования новой личности в современном мире (как динамично развивающийся комплекс социальных, политических, экономических, технологических, коммуникационных, моральных и других компонентов в совокупности с природой, с которой у человека двойственное отношение), инициируемой в пределах цифрового пространства. Для достижения поставленной цели необходим анализ данного процесса как специфического мифотворчества, $m$. $к$. плюралистическое содержание цифровой области способствует формированию элементов, не свойственных объективной реальности, создавая алиби происхождения (легитимность и правдоподобие выстроенной индивидуализации наличествуют и не требуют эмпирической проверки). Кроме того, в работе необходимо вскрыть формирование в современном мире нового соотношения религиозного и атеистического, принимающего форму «обожествления», «богоподобия» личности как некоего явления атеизма в цифровом пространстве. Атеистическое в данном случае является показателем радикального антропоцентризма и эгоизма, способствующим созданию некой абсолютной и исключительной индивидуальности, что впоследствии влияет на сознание, отнотение и поведение человека. Религиозное имеет двойственный характер: с одной стороны, девальвация традиционно религиозных представлений является условием создания индивидуальности с абсолютными и желаемыми качествами, с другой - мифологизация как процесс мистификации становится эффективным орудием для реализации различных, даже радикально-репрессивных тенденций. Методы: диалектический метод как инструмент рассмотрения внутренних противоречий, которые находят своё проявление в генезисе и последующем функционале новой индивидуальности, в частности для выявления двойственности состояния в цифровом пространстве: мнимая автономность/категорическая гетерономность, индивидуализм/репликация, самоопределение/отчуждённость; метод анализа аутентичности (как соответствие позиционирования и содержания), отношения, сознания и поведения современного индивида в цифровом пространстве для выявления соответствия позиционированному и наличествующему содержанию. Это необходимо для синтезирования полученных результатов. Кроме того, данный метод направлен на выявление современных тенденций мифотворчества в аспекте «обожествления» собственной индивидуальности в цифровом пространстве как формы атеизма. Метод моделирования позволил сформировать характерные черты цифровой личности, отражающие содержание создаваемой индивидуальности. Также использовались элементы этического и психологического подходов для выявления специфики поведения и мышления цифровой личности, в частности для раскрытия особенности «нравственности» двойных стандартов и стереотипного (массового) типа ментальности. Выводы: цифровое пространство способствует внутреннему опустошению индивида, что приводит к искажению подлинной личности и подчинению её системе цифрового пространства. Процесс «перестройки» личности снимает с индивида ответственность и инициирует его «обожествление». Генезис «новой личности» имеет автопойетический характер, который в действительности создаёт лишь копию 
цифрового пространства. Состояние «божественности» в цифровом пространстве является современной формой эгоцентризма, антропоцентризма и атеизма.

Ключевые слова: Автономное искусственное пространство, мифотворчество, новая индивидуальность, экзистенциальный вакуум, обожествление, редукция, автономия, атеизм.

Основной вопрос, на который отвечает данная работа,- является ли цифровое пространство (со своим благотворным мифотворческим компонентом) средой, способной сформировать индивидуальность, создать новое её содержание, или же она лишь скрывает репрессивную гетерономность. Несомненно, что данное пространство может служить эффективным инструментом для развития индивидуума, раскрывая те или иные его качества и свойства, предоставляя необходимые возможности и материалы. Но остаётся неоднозначным то, действительно ли цифровое пространство (1) является стимулом формирования индивидуализации и самоопределения, или же эти процессы в нём носят лишь эфемерный характер, а создаваемый образ самости лишь фиктивен и по своему содержанию является лишь слепком области, в которой он формируется.

Одним из фундаментальных желаний для человека являются стремление реализации расширения своих возможностей и модернизация характеристик своего существования. Это, в свою очередь, затрагивает два фундаментальных для человека феномена время и пространство, - которые оказывают позитивное либо негативное влияние на его акторские возможности и предопределяют возможность или невозможность инкарнации того или иного стремления индивида. Действительно, человек всегда стремился во все времена расширить своё пространство (область своего присутствия и распространения своих возможностей) и обуздать время, которое, как и пространство, часто сковывает индивида в процессе попытки реализации желаемого (2). Иными словами, оба этих феномена могут быть как катализаторами, так и ингибиторами осуществления тех или иных целей индивидуума. Несомненным является тот факт, что объективное пространство не всегда имеет достаточно ресурсов для осуществления тех или иных действий и желаний индивида. Также и время - оно относительно объективно для каждого отдельного человека в рамках его существования в объективном мире (т. е. во внешних, в частности природных, условиях, которые обеспечиваются движением планеты). Однако индивид с самых древних времён стремился к контролю времени: умению его останавливать, замедлять, ускорять и т. д. Следы подобных идей можно обнаружить как в мифологии различных религий, так и в работах различных фантастов. Индивид всегда искал инструмент для обуздания локально-темпоральной категоричности внешнего мира. В современном мире такой сферой, где время и пространство теряют свою репрессивную функцию, является цифровая реальность.

Цифровое пространство является искусственной территориальной автономией (3), обладающей своими собственными пространственными и временными характеристиками, которые предопределяются и формируются законами, главенствующими внутри этой зоны. Такая внутренняя архитектоника указывает на то, что виртуальное пространство по своим характеристикам аналогично феномену игры (4). Влияние объективного мира в нём сводится к минимуму, наличествует тенденция к его репрессивному упразднению, а возможности этой своеобразной независимой онтологической области имеют потенциально бесконечные характеристики. Подобное изобилие возможного, открывающееся благодаря специфике информационно-цифрового мира, способствует инициированию и формированию благотворной почвы для различных мифотворческих процессов. Автономия исключает необходимость подтверждения, в том числе эмпирического и практического характера. Создаваемые искусственные мифоло- 
гемы являются действующими, определяющими и влияющими, в частности на сознание индивида, не только внутри этого пространства, но и вне его пределов. Происходит их эманация через человека, являющегося частью объективной реальности. Через сознание, мышление и отношение индивида они укореняются как некие объективные и наличествующие явления. Этот аспект важен для понимания интенсификации и эскалации мифологизации в различных сферах, как в человеческой деятельности, так и в области онтологических вопросов.

Цифровое пространство инициирует процесс деконструкции личности. Таким образом, оно представляет собой особую область личностной редукции и регрессии, где индивид способен «обнулиться», «истощить» своё внутреннее содержание и опыт, базирующийся на взаимодействии с объективной реальностью. В этой автономии индивид может абсолютно освободиться, по крайней мере, в его личном самоотношении и самоопределении, от груза объективного прошлого, которое составляет немаловажную часть его внутреннего содержания. Будучи автономным, цифровое пространство делает индивида «пустым» и «бессодержательным», т. к. ликвидирует довлеющий примат, а иногда придаёт сознательному «забвению» имеющееся содержание личности (5). Одновременно оно позволяет заполнять возникшее вышеуказанное отсутствие новым содержанием, которое ему предоставляется в более широком диапазоне возможностей, нежели это позволяет объективный мир со своими качествами, характеристиками и границами, которые не предполагают такую широкую вариативность (6). Благодаря мифотворческим тенденциям цифрового пространства создаётся совершенно иная, а часто и радикально противоположная изначальной, личность. В ней вакуум заполнен таким содержанием, которое актуально для конкретного индивида. Это то, чем человек хотел бы быть, чего он желал бы для себя, его самые сокровенные желания, в некоторых случаях сформированные социальными стереотипами, либо навязанные ему. В данном случае можно утверждать, что происходит подмена понятий: «быть таковым» подменяется «представляться таковым»/«представлять самому себе себя». Первое предполагает долгое становление через реальное/настоящее в будущее, развитие, прогресс и динамику, второе - воображаемо, это статика, т. к. наличествует изначально, т. е. не требует напряжения и усилий, лишь утверждаемо, но не действительно наличественно.

Стоит отметить, что цифровое пространство для индивида представляет собой некую сферу деэскалации психической нагрузки и экзистенциального давления, в частности со стороны феноменов объективной реальности. Отметим, что подобная «разрядка напряжения» была свойственна некоторым архаическим религиозным практикам, т. к. в процессе сакральных действий индивид освобождается от различного рода запретов, в частности определяющих его статус и место в группе, возводя каждого в некий первоначальный абсолют. Но в воздействии цифрового пространства, в частности как инструмента снятия напряжения, есть и побочный эффект. В процессе трансформации в «нового» индивида происходит «сужение личности», при котором наблюдается снижение напряжения сознания, снижение тонуса, возникает паралич воли, личность распадается (части её начинают действовать бесконтрольно), сужается интеллектуальный кругозор, а всему этому сопутствует рост эгоцентризма и пассивности перед объективными трудностями. И как следствие происходит развитие негативной сущности личности как свидетельство искажения подлинной [1, с. 258]. Цифровое пространство как альтернатива объективному миру связано с процессом ретуширования таких экзистенциальных состояний, как страх и отчаяние, в которых пребывает каждый индивид. 
С. Кьеркегор рассматривал страх как определение грезящего духа и указывал, что в отличие от обычной боязни он является действительностью свободы как возможность для возможного [2, с. 59-60]. Но необходимо сделать определённый шаг, чтобы обрести свободу и реализацию возможного, что достаточно сложно зачастую сделать в объективном мире. Виртуальное пространство снимает эту необходимость преодоления. Во-первых, предоставленные возможности его содержания не требуют от человека напряжения и затрат, в частности волевого характера, как того требует объективная реальность. Во-вторых, анонимность и отсутствие чёткой идентификации виртуального пространства позволяют индивиду снять с себя ответственность. В частности, это ответственность (перед собой и другими) за то, чего более всего боится человек - провалиться в своих начинаниях, не преуспеть, проиграть и т. д., т. е. всё то, что его останавливает от конкретных действий, поступков и волеизъявления. При необходимости виртуальная личность может быть реструктурирована (наполнена новым содержанием), что снимает с неё весь прошлый опыт, ответственность и т. д.

Стоит отметить, что С. Кьеркегор считал, что истоком отчаяния индивида является желание избавиться от самого себя [3, с. 36]. Фромм Э. отмечал, что человек не свободен от дихотомии существования, т. к. даже если он хотел, он не может освободиться от духа, а если бы хотел избавиться от тела, то само желание тела жить ему это не позволит [4, с. 91]. Любой индивид, оценивая себя, свои возможности и способности, видит недостатки и изъяны своего существования. Однако не всегда объективная реальность позволяет индивиду не только исключить, но даже нивелировать их, дабы он обрёл стабильность своей экзистенции. Это вызывает желание избавиться от того, что есть сам индивид, т. е. от самого себя и что определяет его таковым. Объективная невозможность или безуспешные попытки реализации данной собственной коррекции возбуждают у индивида постоянное эскалационное чувство отчаяния, которое постепенно становится его постоянным состоянием. Отчаяние инициирует специфическую тенденцию: в состоянии отчаяния наличествует бесконечное превосходство потенциального над реальным, при этом настоящее исчезает в реальности прошлого, а всё возможное из прошлого осмысляется как настоящее [3, с. 31, 33]. Цифровое пространство утверждает идентичность потенциального и реального. Подобное положение вещей имеет спекулятивный характер. Эта автономная область подменяет второе первым. Более того, происходит такая онтогносеологическая редукция, где прошлое исключается как рудимент, а будущее мыслится настоящим, в котором тотально доминирует принцип «всё прямо здесь и сейчас». Можно сказать, что сейчас главенствует манифест реализующегося будущего. «Будущее здесь», «думай и создавай будущее сейчас» и т. д. Некий бесконечный и интенсивный динамизм настоящего девальвирует будущее, первое «пожирает» второе. Для современного индивида будущее уже должно быть готово (реализовано, проявлено, наличествовать), чтобы его можно было употребить. Это пассивность и отчуждённость потребителя, который в своих иррациональных желаниях потребляет всё вокруг [5, с. 99-100]. Для современного индивида нет смысла в долгосрочном будущем, т. к. оно не может быть использовано/употреблено сейчас. В рамках такой парадигмы будущее без быстрой реализации мыслится как нечто неэффективное, бесполезное и неудобное для индивида.

Более того, поведение современного индивида, его отношение к себе, другим и миру буквально пронизаны концепцией собственной исключительности, т. е. своего настоящего, что значение будущего не только мало, но и ставит вопрос, будто после современного поколения ничего не будет. Несомненно, что подобные умозаключения и выводы продиктованы радикальным эгоизмом и антропоцентризмом, которые являются симптомом деструкции современного индивида. 
Стоит указать, что специфика цифрового пространства инициирует возможность потенциально бесконечной реструктуризации индивидуальности, предполагая постоянные бесконечные циклы метаморфозов и перестроений, что подобно концепции космического хаоса, которая встречается в мифологиях различных народов. Ф. Гваттари отмечал, что хаос предполагает неисчерпаемый резерв возможностей и рождение смысла всегда подразумевает овладение всей совокупностью концептуального разнообразия (7), при этом индивид является не цельной персоной, в которой иногда прорывается хаос, но хаотично ветвящаяся сеть событийности [6, с. 224, 230-231]. Стоит указать, что построение индивидуума в рамках такого пространства связано, в частности, с автопойетическими тенденциями (8). Они позволяют создавать многообразие различных производных продуктов. Однако, при всей эксплицитности и фундаментальности автономности и всём многообразии индивидуальностей в рамках цифрового пространства, все они являются лишь производными, но не производящими.

Как и любой машинный тип (Машина), о котором писал Ф. Гваттари, производит свой собственный мир, где отсутствует необходимость в суверенном и автономном индивиде [6, с. 288-290], так и цифровое пространство обладает тождественными качествами. В границах этого мира есть только то, что ему соответствует, т. е. только то, что является его отражением и продолжением. Машина в своей абстрактности доходит до определённой формы садизма, люди строят систему, а затем сами повинуются ей, как мертвецы [7, с. 257]. Это парадокс: люди - сами творцы цифрового пространства, но, находясь в нём, они искажают себя до неузнаваемости, чтобы являться его частью, предполагая, что именно это индивидуальность. Любое желание, как и любое проявление, - это лишь отпечаток подобной машины на воображаемом мире человека [6, с. 81], это мёртвые желания, питающиеся иллюзиями, ибо система не может допустить живого желания, т. к. оно уничтожит её [8, с. 67]. Требования к качеству жизни свелись к требованиям количественным [6, с. 205], а качественные ценности избегаются, и мир рассматривается в парадигме коммерциализации [7, с. 150]. Подобные тенденции свойственны и современной объективной реальности, однако особой интенсивности они достигли в пространстве цифровом.

Х. Ортега-и-Гассет указывал, что для современного мира характерно состояние переполненности и столпотворения и что найти себе место становится вечной проблемой $[9$, с. 4]. Практически безграничное пространство цифровой реальности способно решить эту проблему (не физически, но экзистенциально, как место существования в противовес активной деятельности в объективном, материальном мире).

Стоит указать на отличительные черты, указывающие на цифровой тип личности. Первая отличительная черта состоит в том, что индивид способен создавать индивидуальный и автономный (относительно) собственный мир, но радикально зависимый и определяемый самим цифровым пространством, т. к. оно становится фундаментом и «границами» подобного построения. Ярким примером могут служить современные «социальные сети» и сайты, где каждая «страница» позиционируется как некий мир (пространство), созданный и заполненный определённым индивидом. Подобное вызывает особое чувство экстаза от креационистских способностей, которые в действительности лишь иллюзорны и воображаемы (9) в большинстве случаев, и являются чрезмерной личностной переоценкой. Особенно по причине того, что истоком таких «мирков» является не индивид, а сама цифровая реальность. Индивид лишь воплощение её тенденций и актуальностей. Вторая отличительная черта заключается в том, что содержание подобного созданного индивидом «мира» внутри цифрового пространства мыслится как нечто совершенно личное, что сформировано им только для него. Это нечто 
сокровенное, потаённое, что иногда приобретает статус практически нуминозного завета (10). Однако при всей «таинственности» и «закрытости» эти «сакральности» осознанно выставляются на всеобщее обозрение, по крайней мере, для тех, кто допущен к этому миру, с целью удовлетворения личных потребностей, которые, по сути, есть требования цифрового пространства. Во-первых, это необходимо для того, чтобы ощутить своё величие, превосходство и индивидуальность. Хотя многие элементы, символы и атрибуты этой «индивидуальности» ей самой и не обладают, а лишь навязаны общими тенденциями именно цифрового пространства, которые и определяют статус индивида. Во-вторых, это необходимость получения одобрения, которое как раз и питает эти «величие» и «индивидуальность». Навязанные тенденции цифрового пространства экстраполируются на реальность. Лайки в социальных сетях, одобрение, быть в тренде, актуальным и т. д. пытаются перенести в объективный мир как критерий самости и особенности индивида, что часто диссонирует с содержанием объективного пространства.

Позиционирование цифровой личности в данном аспекте очень связано с феноменом игры. Кайуа Р. указывал, что игра почти всегда носит зрелищный, даже показной характер и выставляет тайны напоказ, предает огласке, растрачивает их [10, с. 44]. Таким образом, в рамках цифрового пространства индивид обладает внутренней тенденцией к развенчиванию «сакральности» и «тайны», предоставляет это на обозрение, что имеет значение как для него, так и для того, кому это «раскрывается». Такая тенденция имеет особую телеологию. Во-первых, «набить цену» своей «индивидуальности» и самому себе на фоне окружающих. Во-вторых, некое «особое откровение», которое буквально «обожествляет» и «сакрализирует» его автора в глазах других, кто входит в его искусственный мир. В-третьих, указать на добрую волю «хозяина пространства», который буквально снисходит до своих «подданных» и дарует им «кусочек своего возвышенного состояния», отмечает и «благословляет». Однако показательность/наглядность/ некая внешняя ясность может быть лишь маской с целью скрыть пустое содержание того, что позиционируется. Гиперболическая эстетизация позволяет скрыть бессодержательные недостатки подобных «сакральностей», параллельно объединяя всеобщую доступность для других и «сакральность». Подобное имеет своей целью утверждение производящего элемента - цифрового пространства и унификации личности в соответствии с ним.

Следующая характерная черта - цифровая личность - по своим характеристикам подобна «кибернетической личности». Э. Фромм указывал, что такая личность, хотя и оперирует рациональными категориями в своих актах, а её отношение к окружающему миру носит познавательный характер, имеет очевидное и категорическое потребительское отношение к миру, недостаток эмоциональной чувствительности, высокую степень нарциссизма, склонность к стереотипным моделям поведения и шизофренической навязчивости [11, с. 457-458]. Подобная личность настолько вписана в автоматизированную систему, что создаёт с ней симбиоз, в котором машина становится объектом её нарциссизма (подобная личность любит всё автоматизированное, машинное и механическое как себя) [11, с. 458].

Ещё одной характерной чертой является то, что у цифровой личности можно отметить особенность внутреннего построения, состоящую во фрагментарности её архитектоники. Дело в том, что некое желаемое состояние индивида, которое он предполагает как постоянный элемент своей экзистенции (роскошь, особая одухотворённость и т. д.), является лишь фрагментом, зафиксированным в цифровом пространстве. Вся личность, формирующаяся в цифровом пространстве, строится из подобных разрозненных фрагментов. Дело в том, что только эти моменты имеют значение, ведь только они 
желаемы и должны составлять содержание индивидуальности. Остальное, что не попадает, не проходит «проверку на пригодность», как рудимент, необходимо предать забвению. В данном случае отсутствует целостность существования, каждый новый желаемый момент автономен и не связан с другими. Он является исходной точкой экзистенции. Такая фрагментарность не является чем-то скрепляющим личность в реальности, но в цифровом пространстве данное положение вещей эффективно для постоянно перестраивающейся индивидуальности. Эта фрагментарность таргерирована на формирование двух важных моментов. Первый состоит в том, чтобы создать для других, кто находится в искусственном мире конкретной цифровой личности, впечатления, что это постоянное её состояние. Ведь им не доступно ничего, что выходило бы за пределы предоставленного. Второй аспект предполагает, что сам тот, кто позиционирует определённое своё состояние, находится в некоем постоянном экстатическом предвкушении, которое поддерживает иллюзию наличия этого состояния в следующем фрагменте (слепка желаемого состояния) (ощущение от первого фрагмента как бы растягивается в результате подобного чаяния, до наступления нового, в котором актуальность первого теряется и человек полностью погружается в новое). Инициализация такого положения вещей может иметь место только в рамках цифрового пространства, т. к. столкновение с объективной реальностью может разрушить данную искусственную мифологическую конструкцию.

Существует ещё несколько важных отличительных черт, которые присущи цифровому типу личности. Для неё фундаментальным и неотъемлемым является патологическая, практически навязчивая и невротическая зацикленность на новаторстве. Стоит отметить, что в большинстве случаев оно носит сомнительный характер по причине абсурдности и иррациональности. Новаторство в данном случае имеет специфику «вируса», т. е. явления агрессивно-заражающего и передающегося (особо восприимчивым, у кого отсутствует иммунитет - собственная индивидуальность). Новаторские идеи в цифровом пространстве - это не только нечто, что не проходит испытания и экспертизу, хотя бы разумом и логикой, но и принимается большинством как нечто возвышенное и великое. Ведь постоянно изменяющееся цифровое пространство требует от своих «жителей» быть соответствующими ему, однако вопрос содержания этого «нового» упускается и девальвируется. Быть всегда, везде и во всём инновационным и актуальным - это единственное, что необходимо, даже при условии, что это требует отказа от своей индивидуальности и репрессии автономности. Несомненно, что в процессе становления желаемой эфемерной индивидуальности многие готовы это сделать (11). Данный аспект «новой» личности тесно связан с радикальной эстетизацией, которая имеет сильное влияние на современного индивида. Ф. Ницше отмечал, что чем абстрактнее истина, которую необходимо преподать, тем сильнее необходимо обольстить ею и чувство [12, с. 112]. Особая спекулятивная актуальность обращения к радикальной эстетизации требуется тогда, когда речь идёт не только об абстракции, но и о чём-то, что имеет иллюзорный и эфемерный характер. Подобное необходимо для того, чтобы доказать состоятельность и наличествование объекта/предмета/иллюзорной концепции, на которую направлен данный процесс.

Для цифровой личности существует специфическое, расщеплённое и деформированное понятие нормальности. Парадокс данного феномена заключается в искусственной консолидации концепции главенства бесконечности, разнообразия и безмерности (12) и понятия «нормальности» (13) (т. е. некоторого «эталона», модели и т. д.), которому должен быть идентичен каждый индивид в цифровом пространстве. Однако такое искусственное синкретическое сплетение, сплав, контаминация создают в действитель- 
ности однородную структуру пространства, в котором отсутствует как плюрализм, так и нормальность, а существует лишь механическое воспроизведение. Стоит также отметить, что для цифровой личности свойственно особое чувство гиперболической самости (14) и значимости. Они сливаются в формирование особого принципа, согласно которому всё, что ни происходит с подобным индивидом, настолько особенное и исключительное, что никому другому этого не понять, а стоит лишь восхититься внутренними качествами этого человека (15). Хотя в большинстве случаев всё не только тривиально, но и мистифицировано до состояния объективного явления.

С развитием цивилизации, в том числе в рамках интенсивного научнотехнического прогресса (16), который может принять форму технологической сингулярности, место в мире и самоощущение человека становились всё более неоднозначными. Очевидной становится дихотомия человеческого существования: материальное положение человека однозначно стало комфортнее и благополучнее, но вместе с тем инструментальный (17) характер прогресса толкает индивида к обыденности, одиночеству и пустоте. Современному индивиду особенно тесно в пространстве объективной реальности с её локальными и темпоральными ограничениями, что вызывает в нём различные деструктивные тенденции, в том числе отчуждение от самого себя, потерю самоопределения, акторское забвение и т. д. В определённый период человеческой истории религия была способна временно компенсировать вышеуказанный пространственно-временной дефицит, инициируя автономное эмансипированное (свободное от опеки и зависимости от объективного мира) пространство и время (18). Однако по причинам индивидуального характера, а также определённым кризисным тенденциям внутри религии, таким как явления социального и институционального характера, данный инструмент компенсации не стал оптимальным и всеобщим. Кроме того, стоит указать, что на протяжении всего существования религии присутствовали антирелигиозные индивидуальные и групповые тенденции, которые могли трансформироваться в прямое отрицание и попытки её полного запрета и уничтожения. Критике подвергался не только институт, но и объект поклонения - боги или Бог. Более того, с течением времени сформировалась иная тенденция отношения с нуминозным, а именно прямое соперничество с религией и Богом (богами) в стремлении доказать его эфемерность и релятивность. Различные научные достижения, исследования по клонированию, генная инженерия, генные модификации, эксперименты с искусственным геномом, гендерные трансформации и модификации, работы в области искусственного интеллекта и т. д. это не только достижения прогресса, но и доказательства человеческой творческой способности, которая противопоставляется силе объектов поклонения в религии.

В вышеуказанных тенденциях можно отметить стремление к формированию легитимности на особенность и уникальность человека (как создателя, креатора, активного начала) по отношению к неким создаваемым объектам и одновременно возможность компенсировать желания исключения своего экзистенциального одиночества. У индивида в настоящее время присутствует особенно острая необходимость в некоем разнообразии как внутри, так и вне себя. Таким образом, он старается компенсировать в себе определённые кризисные тенденции. Закрытая система человечества, в частности социальная, онтологическая и т. д., требует этого многообразия, дабы не разрушиться по причине ослабления и деструкции внутренних её элементов. Естественная система способна сохраняться многообразием как, например, в природе. Цифровое пространство может стать той платформой, которая может это многообразие предоставить.

Лишь немногие в объективной реальности могут относительно нивелировать налагаемые на каждого индивида ограничения, в том числе пространственные и вре- 
менные, особенно если их истоком являются аспекты социально-экономического характера. В цифровом пространстве многие ограничения, которыми связан индивид в реальном мире, не имеют своей силы, благодаря локально-темпоральной автономии. Влияние времени и места объективной реальности на цифровую автономную область происходит лишь ввиду того, что они фиксируются индивидом, который пребывает в цифровом мире, но одновременно имеет связь (например, физически) с миром материальным. Например, его привычка к времени и пространству реальности могут переноситься в цифровую реальность, ибо, по сути, это его форма существования/мышления, которая дана ему от рождения.

Суверенность определяется специфическими качествами: пространство цифрового мира отличается более широким спектром возможностей для индивида и снятием различного рода ограничений, а само оно потенциально безгранично (19). Время также имеет свои автономные характеристики: оно или течёт по своим правилам, или полностью может быть поглощено цифровым пространством (20). Несомненно, нельзя утверждать, что индивид не чувствует времени в цифровом пространстве. Дело в том, человек не перенесён в него абсолютно, поэтому у него остаётся связь с объективной реальностью, и, соответственно, категория времени экстраполируется в это пространство. Абсолютизм погружения исключается по причине того, что будет иметь место ощущение и восприятие индивидом времени и своего местоположения как явления материального мира. Эти аспекты являются неким маяком, лазейкой, через которую время экстраполируется в цифровое пространство, где отсутствуют временные характеристики. Хотя есть и моменты разрыва с реальностью, ощущение того, что времени нет. Это ощущение отсутствия себя в объективном мире, возникающее при погружении в цифровое пространство. Однако объективная реальность в аспекте индивида всегда прорывается. Здесь критериями, сигналами подобного прорыва могут служить физиологические особенности состояния присутствующего в цифровом мире: голод, сон, усталость, внешние раздражители и т. д.

Подобная автономность от довлеющей власти объективной реальности влияет на самоидентификацию индивида. Переплетаясь с концепцией исключительности и желанием исключения экзистенциального одиночества, она порождает специфическое стремление приобрести иное существование, отличное от имеющегося у других. Стоит отметить, что при всём желании иметь некоего компаньона по существованию, дабы утолить жажду отсутствия одиночества, тем не менее обязательным условием является то, что это нечто другое должно быть ниже его. Хотя, несомненно, что компаньон должен обладать интеллектом для того, чтобы оценить это «величие» и осознать свою «низость». Это другое должно уступать ему в каких-то его качествах и способностях. Антропоцентризм и эгоизм преобладают над этим желанием наличия иной отличной онтологической единицы.

Подобное положение вещей также стимулируется кризисом традиционных форм самоидентичности (21) и снятия экзистенциального напряжения, таких как религия и искусство. Эта политика исполнения желаемого, реализованная в цифровом пространстве с его особенными качествами и характеристиками, приводит к формированию навязчивой и параноидальной идеи «стать Богом», обожествлению своих качеств и самого себя (22). Это не просто желание сравниться с ним, т. е. приобрести аналогичные качества. Подобная «телеология» и «теогония» предполагает более радикальный результат: занять его место, а через приобретённую «божественность» получить освобождение от ограничений и напряжения объективной реальности. Относительно безграничное цифровое пространство позволяет снять социальные, моральные и другие 
ограничения и даже избавить от неотвратимых границ времени и пространства. Несомненно, что это имеет лишь иллюзорный характер и не распространяется на материальное существование индивида. Современный индивид находится в некоем «экзистенциальном вакууме». Он пуст, т. к. у него наблюдается массовый отказ от различных традиционных установок, а новые находятся лишь на стадии формирования (собственного, группового и социального). Ввиду отсутствия чётко направленного вектора развития, индивид становится предоставленным самому себе. Он приобретает легитимность на любую форму становления, т. е. он может стать кем пожелает. Это состояние безграничной возможности переформирования и инициирования череды фундаментальных метаморфозов. Но подобное положение вещей - лишь энтелехиальная предпосылка. Дело в том, что при столкновении с объективной реальностью для большинства этот принцип оборачивается крушением собственного мировоззрения, а затем - следованием необходимости. Цифровое пространство, наоборот, способствует подобному становлению и формированию, благодаря своим исключительным качествам.

Стоит отметить, что для цифровых «богов» характерно особое богоборческое настроение, корни которого лежат в попытке утверждения самости и индивидуальности (единственности). Традиционные представления о Боге/богах становятся в подобной парадигме той концепцией, которая подвергает сомнению личное, антропоцентричное «обожествление». Стоит указать, что любое ограничение абсолюта, установление для него границ и рамок, делает его конечным и относительным, а следовательно, снимает статус объекта «божественного», нуминозного, «совершенно иного». Таким образом, любую критику подобных цифровых «божеств» и их качеств, любую идею, ставящую под удар выстроенную ими картину собственной «божественности» и исключительности, необходимо пресекать и отвергать как рудимент. Особенно если какая-либо идея говорит о чём-то, что превышает их по качествам, способностям и сущности, т. к. стоит только указать на слабость этих цифровых «богов», усомнится в их силе, «пустить кровь» позиционируемому абсолюту, как этот миф моментально развенчивается.

Само понятие Бога/богов как некоего феномена, стоящего выше индивида (т. е. самого себя), отрицается как нечто рудиментарное и эфемерное. Статус божественности определяется обыденным сознанием на основании тех возможностей, которые наличествует у существ. Они должны быть выше, чем у обычных «смертных». В идеале же такие возможности должны быть безграничны, хотя бы формально (23). Цифровое пространство представляет собой сферу для безграничных возможностей, по крайней мере, в рамках собственной компетенции.

Важное место в «обожествлении» имеет аспект поклонения и наличия подданных. Несомненно, в данном явлении прослеживается внутреннее желание признания, славы, влияния и т. д. И именно это способствует укреплению и становлению «божественности», в которой индивид стоит выше других, и они признают его качества, что превышают их собственные. Подобное особенно характерно для активных участников социальных сетей, блогов, Твиттера, Инстаграма и т. д. Подобно политеистическим божествам, этим цифровым «богам» необходимо почитание, и им поклоняются, чтобы получить их благословение (на них обратили внимание, поддержали). Подобно богам Месоамерики, они нуждаются в жертвах (время, внимание и т. д.), для того чтобы жить и восстанавливать свои силы, и соответственно, поддерживать мир, в котором живут «подданные».

Становление цифрового «божества» инициировано часто внутренней (осознанной или неосознанной) ненавистью к себе (собственной форме наличествования и качеству существования) или же вследствие чувства гнетущего ресентимента. Подобная тенден- 
ция вызывает острую необходимость в первом случае переделать себя, трансформировать, «перекроить» во что-то совершенно «иное», отличающееся от других, превышающее других, иными словами, в существо иного порядка. Во втором случае - приобретение качеств, дабы заглушить чувство ресентимента, через доминирование и девальвацию других индивидов, устанавливая свою индивидуальность как абсолют и эталон. При этом в подобной «перекройке» главенствует принцип: чем быстрее процесс и меньше требуется усилий для изменений, тем лучше и приемлемее тот или иной метод для данного процесса. Поэтому цифровое пространство выигрывает у объективной реальности, т. к. даёт всё необходимое по сравнению со второй, где подобные изменения требуют больших ресурсов, времени и усилий. Стоит отметить, что для создания этого «иного» используются различные формы и методы для реализации данного желания, иногда даже деструктивного характера. Подобная «перекройка» может относиться как к неким внешним аспектам (например, внешность, одежда и т. д.), так и внутренним.

Стоит указать, что многие индивидуумы рассматривают цифровое пространство, в котором они пребывают, как личное, созданное для них и только ими, в котором, в отличие от объективной реальности, они центр и интерпретируют себя как исток бытия этого пространства. Такая идея интерпретируется ими как их особый аспект креатора, творца, создателя и т. д. Подобный мифологизированный креационизм даёт ощущение «обожествления», особенно если подкрепляется восхищением поклоняющихся (принятых этим творцом в свой мир, как бы создавшим этих подданных). В действительности, цифровое пространство само по себе пустое и заполняется внутренним содержанием индивидов (как реальным, так и воображаемым) (24), которые как бы формируют и оформляют его. Огромное количество маленьких, альтернативных миров формирует практически неограниченное пространство, что вызывает у индивидуума чувство некой избранности. Это чувство особенности подпитано радикальным эгоизмом (антропоцентризмом), в итоге подводя к идее о собственном радикальном превосходстве над другими, и может трансформироваться в форму насильственного доминирования.

Цифровые «боги» создают особую мифологию (25) вокруг своей персоны, которая утверждала бы легитимность на «особый» статус. В любой традиционной мифологии различных народов существует особый период космологии/космогонии, когда происходит столкновение разных поколений или классов богов. В рамках цифрового пространства это противостояние «богов» представляет собой борьбу за свою особенность, актуальность, индивидуальность. Это схватка за свой «тренд», т. е. за всё то, что делает каждого из них особенным, а впоследствии - «обожествлённым». Подобное положение вещей можно назвать неким «естественным отбором» современного технологического цифрового мира (26).

В погоне за «собственной особенностью», в борьбе за доминирующее положение разрушаются такие границы, которые являются фундаментальными как для социума, так и для индивида. Цифровое пространство рождает не только «богов» или «героев». «Герои» цифровой реальности - это определённые индивиды, которых возносят, высоко ценят, но не «обожествляют». Однако как в отношении подобных индивидов, так и тех, кто обожествляет самого себя, справедливо высказывание Ницше Ф.: «...в мире больше кумиров, нежели настоящих героев» [13, с. 8]. Это пустые и бессодержательные идолы, которые требуют бессмысленных жертв от своих поклонников временем, своей жизнью, материальными благами и личностью (требуется абсолютным мимесис и имитация, нивелирование индивидуальности).

Также в рамках этой плодовитой области рождаются «чудовища» и «монстры» (как и в мифологических традициях), преисполненные разрушительными и всепожи- 
рающими тенденциями (социального, нравственного, культурного и другого характера), в том числе направленными на самих себя и своё окружение. Их деяния носят деструктивный характер, но тем не менее часто привлекают внимание и становятся примером для подражания для тех, кто хочет занять место в некоем «цифровом пантеоне богов». Р. Отто указывал, что жуткое, чудовищное и грубое есть определённые аспекты в развитии нуминозного [14, с. 75, 188, 206]. Кроме того, стоит указать и на аспект контраст-гармонии, присутствующий в становлении нуминозного чувства: чем более ужасающим нечто является, тем более притягательно-волнительным оно будет восприниматься.

\section{ПРИМЕЧАНИЯ}

1. Ц Цифровое пространство представляет собой особую сферу, в рамках которой происходит как преображение и изменение окружающей человека среды, так и создание явлений/вещей, которые не могут существовать в материальной, объективной реальности. Оно непосредственно связано с человеком, являясь продуктом его деятельности, и опосредовано с областью его физического присутствия, но плюрализм возможного и особые качества области цифры становятся теми аспектами, которые не только создают её автономию, но и способствуют транспозиции акторской деятельности, желания и присутствия из материальной сферы в цифровую. К этой области можно отнести не только различные элементы Интернета (социальные сети, форумы, чаты, Твиттер, инстаграмм и т. д.), но всё то, что было оцифровано или подверглось цифровой обработке (виртуальная реальность, кинематограф, фотография, отчасти видеоигры и т. д.). Сегодня, благодаря технологиям, фотографию, как условный слепок реальности, можно обработать так, что она потеряет всякую связь с тем, что на ней запечатлено. Фотографию можно обработать так, что например изображённый на ней человек изменён так (современные средства обработки/фильтры позволяют корректировать образ в соответствии с желаниями: удаление изъянов, изменение формы и цвета и т. д.), что становится не только другим, но и зачастую теряет собственную внешнюю индивидуальность. Подобное и многие другие особенности цифрового пространства влияют на самосознание, самооценку, самоопределение, что в последующем влияет на поведение, мышление и отношение. Исследование цифрового пространства на сегодняшний день носит больше инструментальный характер в рамках парадигмы технических наук для решения конкретных проблем, однако эта сфера вызывает интерес и у гуманитарных дисциплин. Оно представляется более сложным явлением, чем лишь инструмент прикладной деятельности. Более того, цифровое пространство становится местом присутствия индивида, рассматривающего данную область более предпочтительным по сравнению с миром физического присутствия. Проблематика цифрового пространства предполагает рассмотрение его не только как компонента социума, но и в соотношении с природой, в частности посредством материальности человека и его связью с последней. Несмотря на то, что цифровое пространство является как бы альтернативой реальности, имеющейся у человека ввиду его физического существования, тем не менее оно есть продукт деятельности индивида. При исследовании вопроса самоопределения/индивидуализации необходимо использовать опыт, тенденции, а также проблемы данного процесса в объективной (физической, материальной) реальности с обязательной доработкой в соответствии со спецификой сферы цифры.

2. С развитием науки и техники эта экспансия происходит на различных уровнях: начиная от освоения мира элементарных частиц, заканчивая тенденциями освоения космического мира. Кроме того, сам индивид стремится преодолевать различные физические/физиологические ограничения и пределы, в частности в аспекте гендерных трансформаций, и ментальные/психические границы, желая выйти за пределы самого себя. Аспект времени и пространства является тем элементом, спекулирование и манипуляция которыми позволяет инициировать различные метаморфозы.

3. Стоит отметить, что в западной традиции существуют исследования о способах организации мифического пространства в современном плюралистическом дискурсе [15].

4. Игры обладают особой автономией времени, пространства и подчиняются своим собственным внутренним правилам $[10$, с. $46 ; 16$, с. 34-35]. Время и пространство становятся ретрансляторами содержания подобного игрового пространства и не могут выходить за пределы, примат в установлении которых лежит на правилах. Более того, правила и сущность игры в разной степени способны нивелировать и относительно ликвидировать эти феномены, в рамках осуществления игрового процесса.

5. Пространство цифрового мира и игра имеют схожие черты, в частности такие, как автономия. Но как в игре, так и в цифровом пространстве индивид не погружается в него полностью, не растворяется абсолютно. М.М. Бахтин указывал, что индивид не теряет самого себя ни на один момент процесса 
вживания (например, в какую-то роль), и что данный акт не только не создаёт особого места для индивида, но и формирует область бытия, в которой сам индивидуум не принимает участия [17, с. 18-19]. Однако подобное будет справедливо только, когда объективная реальность оказывает постоянное влияние на него. Интенсивность, динамика, содержание и возможность цифрового пространства способны стереть необходимость объективного. Но поскольку цифровая реальность - это нечто «пустое», что требует постоянного заполнения содержанием, различных метаморфозов, непрерывных изменений, таким же становится и сам индивид, впадая в некую экзистенциальную и личностную «амнезию».

6. Ярким примером поиска нового содержания является поиск идентичности женщин в цифровом пространстве, связанный с феминизмом, а также проблематикой различных гендерных мифов и стереотипов [18]. Подобное является одним из многих маркёров, указывающих на содержательную «опустошённость» современного индивида и необходимость поиска компонентов, способных выстроить их внутреннюю архитектонику. Цифровое пространство в данном случае рассматривается как сокровищница строительного материала, однако вопрос его качества является проблематичным.

7. Ещё Ф. Ницше отмечал, что «плодовитым бывает только то, что богато контрастами» [13, с. 38]. Однако стоит указать, что «величайшие заблуждения берут начало не в бесплодии нашего мышления и находчивости, но в излишне обильном плодородии» [19, с. 50]. Состояние излишек и обилия свойственно как цифровому пространству, так и современному индивиду. Например, Х. Ортега-и-Гассет указывал на избыточность как симптом (характерную черту) массового человека [9, с. 68].

8. Как, например у Ф. Гваттари, пойетический потенциал Машины, который сопровождается постоянным воспроизводством её деятельности, предполагает выработку автопойетических продуктов $[6$, c. 254].

9. Ф. Ницше указывал на важность лжи и иллюзий для самой жизни [12, с. 13-14, 25, 61]. Более того он высказывал предположение, согласно которому обман лежит в сущности вещей [12, с. 59]. Б. Паскаль отмечал, что воображение всегда приносит полное и глубокое довольство, какого никогда не испытать «питомцам разума», и в силу своего всевластия над разумом создаёт вторую натуру человека [20, с. 60-61]. Цифровое пространство предоставляет возможность воображению создать желаемую личность, которая тем не менее должна ему соответствовать. Оно помогает не только обмануть и убедить других, но и самого себя до состояния искренней непогрешимой уверенности, а иногда и в форме некой религиозной веры.

10. Ярким примером являются различные социальные сети, блоги, Инстаграм и т. д. Каждая страничка индивида - это нечто совершенно идеальное, наполненное только личным, собственным и желаемым, т. е. тем, что отражало бы величие этого креатора. Ф. Ницше отмечал, что существует некая идея, тенденция и желание человека заставить всё бытие принять его образ и подобие [12, с. 19]. Для такого индивида совершенен мир, который является отражением не его сущности, а желаемой видимости и эфемерной, экстатически жаждаемой аутентичности.

11. Б. Паскаль указывал, что «нас ослепляет не только привычность понятий, но и прелесть новизны» [20, с. 67]. Несомненно, что отказаться от своей индивидуальности, которая самим же индивидом обесценивается, - малая и незначительная цена для обретения мнимой «личности» и «актуальности». Хотя, по сути, такой человек - лишь реплика и копия, а не самостоятельная единица.

12. Лозунг подобных индивидов можно определить высказыванием Ф. Ницше - «мера чужда нам, сознаёмся в этом; нас щекочет именно бесконечное, безмерное» [12, с. 197].

13. Можно согласиться с тем, что «всякая общепризнанная «нормальность»- не более чем социальный компромисс» [6, с. 106]. Что, по сути, является парадоксальным для пространства, для которого заявляется абсолютная безмерность и бесконечность возможного, т. е. плюрализм абсолютизируется. Тем не менее существует разделение, что в норме, актуально, ново, а что является неприемлемым, устаревшим и т. д., за что индивид может порицаться и осуждаться. В действительности, при подобном положении вещей мы найдём всё тоже массовое сознание, которое драпируется в различные формы моды, новаторства, популярности и т. д. Х. Ортега-и-Гассет указывал, что масса снимает непохожее, недюжинное и лучшее, кто не такой, как все, кто думает не как все, рискует стать изгоем [9, с. 12]. Ф. Ницше отмечал, что заурядный человек не создаёт себе цену, а ждёт оценки от своих господ, он ждёт её, а затем инстинктивно подчиняется ей [12, с. 271-272]. Э. Фромм подчёркивал, что в пространстве, где нормальностью является какая-либо патология, чувствуя свою беспомощность и одиночество, индивид сам получит «сдвиг по фазе» [11, с. 463]. Таким образом, налицо насильственное и механическое подчинение навязанным тенденциям для многих, кто ищет своё место в рамках цифрового пространства. Этот поиск сопровождается разложением индивидуальности и формированием пустой, хаотичной, постоянно меняющейся, фрагментированной личности. 
14. Э. Фромм указывал, что для кибернетической личности (как моноцеребральной) характерен такой тип нарциссизма, при котором интересом и самоцелью является своё Я: тело, способности, умения всё то, что ведёт к успеху [11, с. 458]. Для цифровой личности характерна эта черта. Но есть и определённые акцентуации, когда что-то, присущее этому индивиду, приносящее ему успех, подменяет его самого. В этом также проявляется аспект фрагментарности индивидуальности. Более того, ради успеха сам индивид обожествляет определённую черту, принося индивидуальность в жертву, и делает её объектом поклонения, восторга и копирования для других.

15. Например, для современного молодого поколения свойственна тенденция кичиться своим отчаянием, депрессией и т. д. Действительно, современный мир породил столько форм депрессий и отчаяния, как ни одно поколение. Для любой деятельности и сферы человеческого индивида найдётся своё отчаяние и своя депрессия. С. Кьеркегор указывал, что часто отчаяние позиционируется как нечто редкостное, хотя на самом деле оно универсально, редкостно - не быть таковым в действительности [3, с. 39-40]. Более того, отчаяние склонно к обезьянничеству, здесь можно обмануться, приняв за отчаяние всякого рода бесплодную подавленность, надрывную тоску, которая проходит, не приводя к отчаянию [3, с. 41]. Более того, «обезьянничество» также состоит в копировании отчаяния и депрессии одних другими, ведь это так особенно и новаторски, отмечает особое, отличное от обыденного состояние, которого нет у других. Но подобное не выделяет, а лишь низводит к массе.

16. Э. Фромм отмечал особые деструктивные тенденции технического развития человечества. В частности, он указывал, что оно избавляет человека от интереса к жизни, а также от необходимости использовать свои способности и функции [11, с. 445], наделяет его автоматизмом деструктивности $[11$, с. 451$]$, беспрекословным поклонением прогрессу и готовностью положить на алтарь всё живое своему идолу [11, с. 455], формированием безжизненного мира тотальной автоматизации как мира запустения и мертвечины $[11$, с. 456]. Х. Ортега-и-Гассет отмечал, что техническое развитие и наука в совокупности с либеральной демократией способствуют формированию массового человека, кризиса цивилизации, ограниченности науки и т. д. [9, с. 113-121]. Цифровое пространство не стало исключением как сфера, бросающая новые вызовы человеку в различных сферах: индивидуальная безопасность в киберкультуре [21], политический диалог различных групп и объединений [22], создание новых форм войны [23] и т. д.

17. Х. Ортега-и-Гассет отмечал, что всего в мире стало больше, у человека стало больше возможностей [9, с. 37-38], но подобное перенасыщение удовлетворением, некая полнота - это истощение, увядание, в котором нет стремления к чему-то новому, ибо все желания исполнены и отсутствуют возможность и желание их обновить [9, с. 27]. Э. Фромм указывал, что все современные потребности индивида иррациональны и неконтролируемы, они представляют собой искусственно созданные прихоти, отчуждающие человека от самого себя, делая его пассивным, и всё в его окружении трансформируется в объект потребления [5, с. 98-100].

18. Дж. Ф. Бирлайн отмечал, что «священное время - это совершенно отдельное время для отдельной реальности, лежащее за пределами часов и календаря и отмечающее наши встречи с Вечным» $[24$, c. 25]. М. Элиаде утверждал, что переживание мифа предполагает переход в качественно иное время (в отличие от светского, хронологического), переживающий погружается в особенное временное пространство, заряженное энергией [25, с. 29]. Стоит также указать, что по подобной же причине, т. е. с целью отделить сакральное от профанного, места ритуальных, культовых действий всегда были отделены от другого пространства объективной реальности.

19. Пространство цифровой реальности может вместить то, чего нет в объективном мире, или то, чего не может быть в нём, или не допустимо по тем или иным причинам (по социальным, онтологическим, моральным и т. д.). Аристотель отмечал, что нечто хотя и может существовать, однако не существует, и хотя может не существовать, однако существует [26, с. 255]. Цифровое пространство предоставляет возможность существования, проявления того, что не может или не должно наличествовать в объективном мире по тем или иным причинам.

20. Ярким примером являются видеоигры. Традиционно время в них зависит от игрока или имеет вторичный фоновый характер. Однако разработчики стремятся создать такую игру, где время будет фактором автономным как от воли игрока, так и его субъективного (игрового) времени [27, с. 54-55]. Таким образом, формируется цифровая реальность, совершенно отдельная от материальной. В ней всё, в том числе и время, события, и даже сама локация (её содержание) будут обладать автономией.

21. В западной традиции существуют исследования, которые посвящены вопросу о рассмотрении экзистенции человека через призму постчеловеческого фольклора и трансгуманизма, что предполагает отличное от традиционного понимания человеком своего существования [28].

22. Можно провести аналогию с некоторыми религиозными традициями. Например, инициация и практика каннибализма (в том числе, с присущими ему формами безумия) рассматриваются как отож- 
дествление практикующего с божеством [29, с. 169, 173]. Или, например, идея тотальности существа как совершенства, идеала, божественного феномена [29, с. 74]. Подобная тенденция проявляется в различных культовых практиках переодевания или иных ритуалах для имитации совместимости в одном индивиде двух полов. Интересно, что и в современном цифровом пространстве (особенно в различных социальных сетях) также присутствуют эти тенденции: нравственный каннибализм как форма доминирования, вектор гендерного нивелирования. Хотя они присутствуют и в объективной реальности, однако она уступает в интенсивности и количестве конкретных проявлений.

23. В данном случае можно говорить о некоем суррогате нуминозного чувства. Р. Отто отмечал, что нуминозное чувство предполагает не только ощущение поразительного, бросающегося в глаза, не похожего на меня, но и ощущение того, что это «иное» несоизмеримо больше меня, что будоражит фантазию и вызывает интерес [14, с. 45-46]. Но, кроме того, момент «numen» вызывает ощущение тварности, которое возникает перед лицом огромного всемогущества.

24. Несомненно, что цифровое пространство заполняется и феноменами объективной реальности. Но зачастую важно понимать, какова цель информации, которую размещают в цифровом пространстве (действительно, отразить, то или иное явление или спекулировать на определённой, в частности очень актуальной, теме). Кроме того, необходимо учитывать, что информация, отражённая в цифровом пространстве, может быть подвергнута искажению и деформации по тем или иным причинам. Очень часто те, кто проводит много времени в цифровом мире, принимают его содержимое, в том числе то, что сказывается о мире объективном, как непреложную истину, не требующую проверки.

25. Несомненно, что подобные мифологии имеют определённый религиозный аспект, в частности с целью её актуализации, имеющей прагматический и спекулятивный характер. Стоит отметить, что существуют исследования, указывающие, что для анализа современной технической революции, общества, СМИ и т. д. необходимо обращение к мифологическому аспекту [30].

26. Однако этот процесс происходит не всегда по Ч. Дарвину, а чаще по Ф. Ницше, который указывал, что победа скорее не на стороне сильных и счастливых исключений, а на стороне слабых, которых много, они умные, и богаче духом (под духом он подразумевает осторожность, терпение, хитрость, самообладание и т. д.) [13, с. 81$]$.

\section{СПИСОК ЛИТЕРАТУРЫ}

1. Юнг К.Г. Душа и миф. Шесть архетипов. - M.: Port-Royal, 1997. - 384 с.

2. Кьеркегор С. Понятие страха. - М.: Академический проект, 2014. - 224 с.

3. Кьеркегор С. Болезнь к смерти. - М.: Академический проект, 2019. - 157 с.

4. Фромм Э. Синдром распада // Кризис сознания: сборник работ по «философии кризиса». - М.: Алгоритм, 2009. - С. 82-97.

5. Фромм Э. Отделение от себя // Кризис сознания: сборник работ по «философии кризиса». - М.: Алгоритм, 2009. - С. 97-104

6. Дьяков А.В. Феликс Гваттари, философ трансверсальности. - СПб.: Владимир Даль, 2012. - 592 с.

7. Барт Р. Мифологии. - М.: Академический проект, 2014. - 351 с.

8. Делёз Ж. Шизо-потоки и погребальная аксиоматика капиталистического социума // Кризис сознания: сборник работ по «философии кризиса». - М.: Алгоритм, 2009. - С. 59-67

9. Ортега-и-Гассет Х. Восстание масс. - М.: АСТ, $2018-256$ с.

10. Кайуа Р. Игры и люди: Статьи и эссе по социологии культуры. - М.: ОГИ, 2007. - 304 с.

11. Фромм Э. Анатомия человеческой деструктивности. - М.: АСТ, 2016. - 624 с.

12. Ницше Ф. По ту сторону добра и зла. - М.: Издательство «Э», 2018. - 320 с.

13. Ницше Ф. Падение кумиров: Избранное. - СПб.: Лениздат, Команда А, 2014. - 224 с.

14. Отто Р. Священное. Об иррациональном в идее божественного и его соотношении с рациональным. СПб.: АНО «Изд-во С.-Петерб. ун-та», 2008. - 272 с.

15. Toth M. On pluralist mythscapes. Memory studies. Advance online publication. 2021. URL: https://doi.org/10.1177/1750698020988746 (дата обращения 23.01.2021).

16. Хёйзинга Й. HomoLudens. Человек играющий. - СПб.: Изд-во Ивана Лимбаха, 2011. - 416 с.

17. Бахтин М.М. Собрание сочинений в 6 т. Т. 1. - М.: Русские словари, 2003. - 958 с.

18. Donaldson A.J. The cyber-goddess: women and technology // Journal of Visual Literacy. - 2000. - V. 20. № 1. - P. 31-38. DOI: 10.1080/23796529.2000.11674554

19. Юм Д. Диалоги о Естественной Религии. - М.: Профит Стайл, 2007. - 192 с.

20. Паскаль Б. Мысли. - М.: Астрель, 2009. - 253 с.

21. Cyber culture - myth or reality. Building cyber space survival competencies / G. Zhablyanova, M. Pavlova, B. Tetevenska, K. Bosakova // EDULEARN19 Proceedings: 11th International Conference on Education 
and New Learning Technologies. - Palma, Spain, 1-3 July 2019. - Valencia: IATED Academy. 2019. P. 2480-2485. DOI: 10.21125/edulearn.2019.0678

22. Jones B.L. Cyber creeps: the alt-right and the evolution of social media hatemakers // Platforms, Protests, and the Challenge of Networked Democracy. - Cham: Palgrave Macmillan, 2020. - P. 117-134. DOI: 10.1007/978-3-030-36525-7_7

23. Sharma A. Cyber wars: a paradigm shift from means to ends // Strategic Analysis Strategic Analysis. 2010. - V. 34. - № 1. - P. 62-73. DOI: 10.1080/09700160903354450

24. Бирлайн Дж.Ф. Параллельная мифология. - М.: КРОН-ПРЕСС, 1997. - 336 с.

25. Элиаде М. Аспекты мифа. - М.: Академический проект, 2010. - 251 с.

26. Аристотель. Метафизика. - М.: Издательство «Э», 2016. - 448 с.

27. Ветушинский A. To play Game Studies Press the START button // Логос. - 2015. - Т. 25. - № 1. C. 41-60.

28. Thompson T. Posthuman folklore. - Jackson: University Press of Mississippi, 2019. - 214 p. DOI: 10.14325/mississippi/9781496825087.001.0001

29. Элиаде М. Тайные Общества. Обряды инициации и посвящения. - СПб.: Университетская книга, 1999. - 356 c.

30. Karim H.K. Cyber-utopia and the myth of paradise: using Jacques Ellul's work on propaganda to analyse information society rhetoric // Information, Communication \& Society. - 2001. - V. 4. - № 1. - P. 113-134. DOI: $10.1080 / 13691180110035768$

Поступила 27.01.2021 2. 
UDC 316.772.5:316.612

\title{
DIGITAL SPACE AS AN INCENTIVE FOR THE FORMATION OF INDIVIDUALIZATION AND SELF-DETERMINATION.
}

\author{
Nikolay I. Petev, \\ cyanideemo@mail.ru \\ Vladimir State University, \\ 87, Gorky street, Vladimir, 600000, Russia
}

Nikolay I. Petev, Cand. Sc., associate professor, Vladimir State University.

This article examines the influence of digital space on the formation of personality, and analyzes its specifics. In other words, the author considers the genesis of individuality and personal metamorphoses that are initiated under the influence of the specifics of the digital world. The purpose of the work is to identify the specifics of the formation of a new personality in the modern world, initiated within the digital space, and to analyze this process, which has the character of a specific myth-making. In addition, the paper aims to reveal the formation of a new relationship between the religious and the atheistic in the modern world, which takes the form of «deification», "godlike» of the individual as a phenomenon of atheism in the digital space. Methodology. The dialectical method is used as a tool for considering internal contradictions that find their manifestation in the genesis and subsequent functionality of a new identity. The analytical methodology involves the use of in-depth analysis of the authenticity, attitude, consciousness and behavior of the modern individual in the digital space. This is necessary for synthesizing the results obtained. In addition, this method is aimed at identifying modern trends in myth-making in the aspect of «deification» of one's own identity in the digital space as a form of atheism. The modeling method allowed us to form the characteristic features of the digital personality. Elements of ethical and psychological approaches were also used to identify the specifics of the behavior and thinking of the digital personality, including digital "gods». The comparative method and the religious approach were used to identify the specifics of the myth-making of the modern individual within the virtual space. Results. The author comes to the following conclusions: 1. Digital space contributes to the internal emptying of the individual, which leads to distortion of the true personality and its subordination to the system of digital space. 2. The individual «restructuring» removes responsibility from the individual and initiates his «deification». 3. The genesis of the «new personality» has an autopoietic character, which in reality creates only a copy of the digital space. 4. The state of «divinity» in the digital space is a modern form of egocentrism, anthropocentrism and atheism.

Key words: Autonomous artificial space, myth-making, new identity, existential vacuum, deification, reduction, autonomy, atheism.

\section{REFERENCES}

1. Yung K.G. Dusha i mif. Shest arkhetipov [Soul and myth. Six archetypes]. Moscow, Port-Royal Publ., 1997. $384 \mathrm{p}$.

2. Kerkegor S. Ponyatie strakha [The concept of fear]. Moscow, Akademicheskiy proekt Publ., 2014. 224 p.

3. Kerkegor S. Bolezn k smerti [The sickness unto death]. Moscow, Akademicheskiy proekt Publ., 2019. 157 p.

4. Fromm E. Sindrom raspada [Syndrome of decay]. Krizis soznaniya: sbornik rabot po «filosofii krizisa» [Crisis of consciousness: a collection of works on the «philosophy of the crisis»]. Moscow, Algoritm Publ., 2009. pp. 82-97.

5. Fromm E. Otdelenie ot sebya [Separation from oneself]. Krizis soznaniya: sbornik rabot po «filosofii krizisa» [Crisis of consciousness: a collection of works on the «philosophy of the crisis»]. Moscow, Algoritm Publ., 2009. pp. 97-104. 
6. Dyakov A.V. Feliks Gvattari, filosof transversalnosti [Felix Guattari, philosopher of transversality]. St. Petersburg, Vladimir Dal Publ., 2012. 592 p.

7. Bart R. Mifologii [Mythologies]. Moscow, Akademicheskiy proekt Publ., 2014. 351 p.

8. Delyoz Zh. Shizo-potoki i pogrebalnaya aksiomatika kapitalisticheskogo sotsiuma [Schizo-flows and funerary axiomatics of capitalist society]. Krizis soznaniya: sbornik rabot po «filosofii krizisa» [Crisis of consciousness: a collection of works on the «philosophy of the crisis»]. Moscow, Algoritm Publ., 2009. pp. 59-67.

9. Ortega-i-Gasset Kh. Vosstanie mass [The revolt of the masses]. Moscow, AST Publ., 2018. 256 p.

10. Kaya R. Igry i lyudi: stati i esse po sotsiologii kultury [Games and people: articles and essays on the sociology of culture]. Moscow, OGI Publ., 2007. 304 p.

11. Fromm E. Anatomiya chelovecheskoy destruktivnosti [Anatomy of human destructiveness]. Moscow, AST Publ., 2016. 624 p.

12. Nitsshe F. Po tu storonu dobra i zla [Beyond good and evil]. Moscow, «E» Publ., 2018. 320 p.

13. Nitsshe F. Padenie kumirov: izbrannoe [The fall of idols: favorites]. St. Petersburg, Lenizdat Publ., 2014. $224 \mathrm{p}$.

14. Otto R. Svyashchennoe. Ob irratsionalnom v idee bozhestvennogo i ego sootnoshenii s ratsionalnym [Sacred. On the irrational in the idea of the divine and its relation with the rational]. St. Petersburg, ANO StPetersburg University Publ., 2008. 272 p.

15. Toth M. On pluralist mythscapes. Memory studies. Advance online publication. 2021. Available at: https://doi.org/10.1177/1750698020988746 (accessed 23 January 2021).

16. Kheyzinga Y. Homo Ludens. Chelovek igrayushchiy [Homo Ludens. Man playing]. St. Petersburg, Ivan Limbakh Publ., 2011. 416 p.

17. Bakhtin M.M. Sobranie sochineniy v 6 t. T. 1 [Collected works in 6 vol. Vol. 1]. Moscow, Russkie slovari Publ., 2003. 958 p.

18. Donaldson A.J. The cyber-goddess: women and technology. Journal of Visual Literacy, 2000, vol. 20, no. 1, pp. 31-38. DOI: 10.1080/23796529.2000.11674554

19. Yum D. Dialogi o estestvennoy religii [Dialogues about Natural Religion]. Moscow, Profit Stayl Publ., 2007. 192 p.

20. Paskal B. Mysli [Thoughts]. Moscow, Astrel Publ., 2009. 253 p.

21. Zhablyanova G., Pavlova M., Tetevenska B., Bosakova K. Cyber culture - myth or reality. Building cyber space survival competencies. EDULEARN19 Proceedings: $11^{\text {th }}$ International Conference on Education and New Learning Technologies. Palma, Spain, 1-3 July 2019. Valencia, IATED Academy Publ., 2019. pp. 2480-2485. DOI: 10.21125/edulearn.2019.0678

22. Jones B.L. Cyber creeps: the alt-right and the evolution of social media hatemakers. Platforms, Protests, and the Challenge of Networked Democracy. Cham, Palgrave Macmillan Publ., 2020. pp. 117-134. DOI: 10.1007/978-3-030-36525-7_7

23. Sharma A. Cyber wars: a paradigm shift from means to ends. Strategic Analysis Strategic Analysis, 2010, vol. 34, no. 1, pp. 62-73. DOI: 10.1080/09700160903354450

24. Birlayn Dzh. F. Parallelnaya mifologiya [Parallel mythology]. Moscow, KRON-PRESS Publ., 1997. 336 p.

25. Eliade M. Aspekty mifa [Aspects of myth]. Moscow, Akademicheskiy proekt Publ., 2010. 251 p.

26. Aristotel. Metafizika [Metaphysics]. Moscow, «E» Publ., 2016. 448 p.

27. Vetushinsky A. To play game studies press the START button. Logos, 2015, vol. 25, no. 1, pp. 41-60. In Rus.

28. Thompson T. Posthuman folklore. Jackson, University Press of Mississippi Publ., 2019. 214 p. DOI: 10.14325/mississippi/9781496825087.001.0001

29. Eliade M. Taynye obshchestva. Obryady initsiatsii i posvyashcheniya [Secret society. The rites of initiation and dedication]. St. Petersburg, Universitetskaya kniga Publ., 1999. 356 p.

30. Karim H.K. Cyber-utopia and the myth of paradise: using Jacques Ellul's work on propaganda to analyse information society rhetoric. Information, Communication \& Society, 2001, vol. 4, no. 1, pp. 113-134. DOI: 10.1080/13691180110035768 